\title{
EL INDIVIDUALISMO LIBERAL 1
}

\author{
Sajid A. Herrera Mena*
}

a finalidad de este trabajo es exponer a grandes rasgos las
raíces, los supuestos y el significado del individualismo li
beral.

Decir que el liberalismo es netamente individualista no entraña novedad alguna. Su configuración como espectro ideológico reclamaba una visión cada vez más "monádica": individual, pluralista, no holística y anti-jerárquica. Y su afirmación sobre las libertades individuales era innovadora frente a la concepción antigua: "el gozo pacífico de la independencia privada" 2 .

Que cada hombre construya su mundo, se desarrolle y despliegue todas sus aspiraciones y capacidades sin limitación extema, será el grito de batalla de este pensamiento. Sin embargo, sostener lo anterior requiere algo más profundo y previo: el que cada individuo sea el propietario de su propia persona. Es decir, que los hombres sean autárquicos y dueños de sí mismos ante las voluntades ajenas.

Estos postulados del individualismo liberal han tenido y poseen hoy en día su eficacia no sólo en la vida privada sino también en la pública: en lo político, reduciendo al Estado a un ente "mínimo", guardián exclusivo de las garantías individuales; en lo eco-

* Profesor del Departamento de Filosofía de la UCA. 
nómico, la lucha por extender cada vez más las redes de acción competitiva entre los agentes sociales.

Aun así, la resonancia y las transformaciones de tales principios sufridas a lo largo de estos siglos no se entenderían si no son observados bajo una lente histórica. No obstante, en razón de nuestro trabajo, no nos es posible explorar sus matizaciones a través de cuatro centurias. Nos interesa, más bien, analizar en términos generales los supuestos individualistas del "liberalismo clásico" o del liberalismo del siglo XVII.

Como tendremos la oportunidad de ver en su momento, los enfoques de la idea de "individualismo" en el pensamiento liberal clásico han sido variados. Se puede hablar de una perspectiva ética desde el momento en que se ha defendido a "todo" hombre como sujeto de derechos inviolables e inalienables. Desde un enfoque político se estima que el Estado es un posterius o una creación de los individuos y que por tanto su función será de reconocer y garantizar el respeto a las libertades y pluralidades humanas. En un enfoque más antropológico, los individuos son considerados como átomos libres de las voluntades ajenas y capaces de desarrollarse por su propia cuenta. Y, bajo una consideración mercantil, las relaciones entre los hombres será reducida a relaciones entre propietarios.

A continuación pasaremos a exponer estos enfoques en el siguiente orden: en primer lugar pretendemos introducirnos al liberalismo con nociones muy generales sobre sus múltiples significados y raíces históricas. El segundo apartado lo dividiremos en dos partes: la primera, abordará las raíces modernas del individualismo liberal. La segunda, el significado y los supuestos del individualismo liberal a partir de los estudios proporcionados por Macpherson, Mairet, Bobbio, entre otros. En el último apartado, y muy ligado al anterior, expondremos las dos nociones más importantes que la tradición liberal le ha atribuido al término "libertad": libertad negativa y libertad positiva.

\section{Nociones generales sobre el liberalismo}

omo el epígrafe lo indica, en este apartado expondremos, en
primer lugar, los múltiples significados que sobre el liberalis- 
mo se han vertido a través de su historia. Posteriormente, incursionaremos en su génesis y en sus raíces con el afán de comprender mejor este fenómeno.

Cuando hablamos del liberalismo como corriente de pensamiento, de entrada hallamos un obstáculo y es la dificultad de definirlo. El liberalismo ha sido entendido por autores liberales y por no liberales como un método para comprender las acciones sociales y económicas; como la teorización sobre una forma novedosa de Estado: el nuevo Estado liberal que surge desplazando al poder centralizado y autoritario para garantizar las libertades y bienes individuales. Así, hay liberalismos que puntualizan más en lo político, cuando sus discursos están encaminados a limitar las esferas de acción del poder estatal en la sociedad civil; se ha entendido también como un partido político, es decir, cuando se habla de los partidos liberales; como una doctrina sobre la producción y distribución de bienes: cuando se puntualiza en el ámbito económico al apelar al libre juego de los actores sociales en el mercado.

Ciertamente, además de sus variadas definiciones, el liberalismo engloba una diversidad de posturas tanto modernas como contemporáneas, todas bajo esa misma etiqueta.

José Merquior afirma que el pensamiento liberal "presupone una amplia variedad de valores y creencias..." 3 ; ê゙ ese sentido, no es novedoso que encontremos liberalismos de "armonía" y de "disonancia", liberalismos "conservadores" y "sociológicos", Neoliberalismos, Neo-contractualismos, etc.

En este predominio de los "ismos" subyace la manera de enfatizar algunos de los aspectos o presupuestos más importantes de este pensamiento. Sin embargo, estos énfasis de unos aspectos sobre otros no quedan dispersos e inconexos, pues, tienen su apoyatura en algo común (aunque interpretado de diversas formas): la libertad. Guido de Ruggiero cree que la libertad es "el primer elemento orgánico de la experiencia liberal".4 Es decir, el liberalismo, con toda la riqueza de sus matices y enfoques busca en última instancia el reconocimiento de la libertad de los individuos como un hecho básico y fundante.

Según Merquior la diversidad de credos liberales que evidencian un remolino ideológico en su interior tiene su origen en dos 
aspectos importantes: uno de índole reinvidicativo por cuanto los pensadores liberales exigían el derrumbe de obstáculos hacia una determinada forma de libertad, fuera ésta económica, política, religiosa, etc.; el segundo como complemento del anterior, de índole interpretativo por cuanto ha variado el sentido y la concepción del término "libertad", dando lugar a numerosas redefiniciones y reinterpretaciones.

Por otra parte, no podemos olvidar que el liberalismo es un hecho histórico. Como tal, es una expresión de la Modernidad, pues su progresiva formación y desarrollo a través de los últimos cuatro siglos así lo testifican. El curso de su historia no ha sido una línea triunfalista ni externa ni internamente. Basta señalar sus tropiezos políticos y discrepancias ideológicas para alejar la creencia de un cuadro totalmente idílico y orgánico. Para la tradición liberal, la Revolución inglesa de 1688 contra Jacobo II ha significado el hecho histórico que señaló la puesta en marcha de su ideario, aún cuando sus protagonistas son inconcientes tanto del nombre de sus ideas, como del alcance de las mismas.

Es en ese momento cuando la burguesía inglesa inicia su lucha contra el poder político por mayores grados de libertad civil y económica; por un poder político limitado y dividido; por un respeto o tolerancia religiosa, así como por un fortalecimiento del imperio de la ley o constitucionalismo.

Sin embargo, el liberalismo, en su formación y desarrollo, fue configurado por diversas fuentes modernas. Las ideas de derechos individuales, la secularización de la vida, la tolerancia a la pluralidad de pensamiento, la idea de un progreso humano y económico por medio del progreso científico-técnico, las teorías del contrato social, no son sino algunas de las contribuciones modernas a este pensamiento. Tales contribuciones fueron posibles a través de ciertos hechos históricos como la Reforma protestante, las nuevas relaciones económicas, los métodos racionalistas de la jurisprudencia moderna, las nuevas investigaciones en el campo de la ciencia, etc. Merquior ha denominado a este pluralismo de hechos y de ingredientes, que han constituido al "credo liberal", como protoliberalismo.

El protoliberalismo será "[el] conjunto ideológico de valores e 
instituciones que históricamente preparó el camino para la policidad plenamente liberal... 4 Esta "policidad plenamente liberal" llegó a consolidarse en el siglo XIX con un gran apogeo de la industrialización, en la esfera económica y en el parlamentarismo, a nivel político. Pero ese conjunto de valores e instituciones que preparó esta plenitud liberal debe rastrearse muy atrás. Harold Laski sostiene que "los fundamentos de una doctrina liberal, por decirlo así, se establecen en el siglo XVI"6, *

Fue en los inicios de la Epoca Moderna (siglos XV-XVI) cuando una serie de acontecimientos se fueron constituyendo en semillas de esta mentalidad novedosa. Es por esta polivalencia histórica por la cual no debe concebirse el desarrollo del liberalismo de una manera lineal e inclusive triunfalista, sino como un proceso de muchas direcciones en donde hubo avances y retrocesos. Para Laski, en el desarrollo del liberalismo se entrecruzan una diversidad de corrientes y doctrinas que, ciertamente, complican un traba,o preciso y claro en su abordaje. Aún, él reconoce que contribuyeron a su desarrollo hombres que incluso le eran hostiles o, si acaso, ajenos: desde Maquiavelo hasta Calvino desde Copérnico hasta Lutero, Pascal y Hobbes, entre otros. Ello se debió, a su juicio, tanto a esfuerzos deliberados como a actitudes inconcientes.

2. El individualismo como presupuesto básico y esencial del liberalismo

F $n$ el apartado anterior observamos que el liberalismo no surge Lor ger generación espontánea, sino que se trata de un hecho his-
tórico y que como tal está marcado por los avatares del espacio y del tiempo.

Pero si hay una característica de la modernidad que ha influido tanto en su configuración, de tal suerte que podamos afirmar que es su presupuesto básico, esa es el individualismo.

Por tal motivo, en el presente apartado nos ocuparemos de dilucidar lo que se ha denominado "el individualismo liberal". Para ello será necesario que antes incursionemos en las fuentes o raíces modernas de dicho individualismo, pues éstas nos ayudan a comprender los supuestos de aquel. 


\subsection{Fuentes modernas del individualismo liberal}

¿Qué entenderemos por "fuentes modernas" del individualismo liberal? Por ese término vamos a comprender las tendencias, las corrientes y escuelas de la Epoca Moderna que han contribuido a la formación del espíritu individualista liberal.

Las fuentes modernas que expondremos suscintamente aquí son: 1-) el individualismo de la Reforma; 2-) el individualismo iusnaturalista y 3-) el individualismo económico.

\section{El individualismo de la Reforma.}

Según Ernest Troeltsch la revolución teológica de la Reforma significó, a nivel general, una lucha contra la cultura eclesiástica, autoritaria e intolerante de la Edad Media. Sin embargo, uno de los aspectos que más se le reconocen es su apuesta por una individualidad; una individualidad típicamente religiosa: cada hombre es un ser autónomo de la infabilidad pontificia y por ende lo que prima son sus convicciones personales y el libre examen de su conciencia.

Troeltsch ha afirmado que "no cabe duda que su poderoso individualismo religioso que, por lo demás, no hace sino prolongar la mística y la religión laica de la Baja Edad Media, reviste una significación extraordinaria en el nacimiento del individualismo moderno..."7. Por esa razón Merquior sostiene que de alguna manera el protestantismo colaboró inconscientemente en la formación del derecho a la libertad de consciencia y de pensamiento.

2. El individualismo iusnaturalista.

Para muchos 8 la denominación de "escuela" al derecho natural moderno sufre de una gran limitante: bajo esta etiqueta son ubicados una diversidad de autores, no sólo de distintos períodos de la época, sino, y fundamentalmente, de distintas posturas jurídicas, políticas y filosóficas. Autores como Hobbes, Spinoza, Leibniz, Kant, Pufendorf, etc. son situados dentro de esta "escuela". Sin embargo, los propósitos de tal denominación podrían ser metodológicos, es decir, para diferenciar todo un movimiento heterogéneo del derecho natural moderno frente a una vertiente clásica y medieval.

Se ha dicho que el iusnaturalismo moderno apuesta por el "de- 
recho subjetivo" en contraposición al "derecho objetivo" de las escuelas anteriores. Pero en realidad, lo que existe es una continuidad entre ambos planteamientos. La escuela del derecho natural moderno no disuelve los derechos objetivos, sino los acepta pero vigorizando el ámbito subjetivo: "...el derecho natural va a ser como una norma humana puesta por autonomía y la actividad del sujeto, libre de todo presupuesto objetivo (y en particular teológico) y explicable mediante la razón, esencial instrumento de la subjetividad humana".9

Es necesario aclarar, por otro lado, que el iusnaturalismo ctásico y medieval no fue siempre y exclusivamente una teorización sobre el derecho objetivo. Hubo excepciones, las cuales consideraban a la razón humana como fundamento del derecho natural (p. e. los estoicos). De igual manera hubo excepciones en el iusnaturalismo moderno: no siempre los discursos apuntaban primordialmente a la autonomía del sujeto racional, sino también encontramos casos en los cuales se apelaba a Dios como sustrato último del derecho. Por ello se insiste en que no se puede hablar de una ruptura entre ambas tradiciones, cuando lo que hay es una continuidad superadora de los modernos con respecto a sus antecesores.

Llegado a este punto, veamos algunas de las características del iusnaturalismo moderno. Estas características mostrarán el fuerte individualismo que impregna a dicha escuela.

En primer lugar, la razón humana será la sede del derecho natural, es decir del conjunto de normas y reglamentos que regirán la vida de los hombres. En segundo lugar, y conectado con lo anterior, hay una presencia de un individualismo teórico que se manifiesta concretamente en la concepción de sociedad como mero agregado de individuos, cada uno con sus propios derechos innatos.

En tercer lugar, el Estado se concibe como un artificio, como una gran obra hecha contractualmente por todos los individuos y cuya función es, o bien evitar el daño mutuo entre éstos mediante un poder absoluto y centralizado o preseryar y garantizar las libertades junto con los bienes de los individuos. Este último criterio fue el preferido por los autores liberales y, a juicio de Fassó, 
ideológicamente fue preparando las revoluciones liberalęs de 1688 en Inglaterra y del siglo XVIII en Estados Unidos y Francia.

En cuarto lugar, las doctrinas del iusnaturalismo moderno revisten un carácter "ahistoricista". El supuesto fundamental de este ahistoricismo es la doctrina del contrato social, basada en la existencia de un estado primigenio de los hombres del cual no hay ninguna constatación histórica, pero sin duda alguna "no han faltado ni nunca faltarán hombres en esta condición". En este estado natural, los hombres viven libres e iguales y por diversas circunstancias, entre ellas la guerra, se verán obligados a realizar un convenio o contrato que les permita crear una de las más grandes obras de la humanidad: la Sociedad Civil o el Estado. Esta visión tricotómica, Estado natural-pacto-sociedad civil, está fuera de coordenadas espacio-temporales, por lo que se convierte en una abstracción o en una hipótesis de trabajo, spermitiendo a los iusnaturalistas modernos legitimar las instituciones políticas de su tiempo.

En quinto lugar, tenemos la característica más compartida entre todos los iusnaturalistas modernos: el "método racionalista" "El método que une a autores tan diferentes es el método racional, o sea el método que debe permitir reducir el derecho y lo moral (además de la política), por primera vez en la historia de la reflexión sobre la conducta humana, a ciencia demostrativa"10. La metodología racionalista de la escuela del derecho natural moderno es un ejemplo de como el paradigma científico venía impregnándose en todas las esferas de la vida. Desde esta perspectiva, para los iusnaturalistas modemos las relaciones entre los.individuos serán consideradas como fenómenos naturales, susceptibles de ser observados y aislados en "un medio experimental", como también predecir sus acontecimientos con rigor y precisión matemática.

\section{El individualismo económico}

Para Laski "el movimiento del feudalismo hacia el capitalismo un efecto de la acción socialmente controlada, hacia un mundo en que el bienestar social aparece como un efecto de la acción indivi- 
dualmente controlada. La esencia de esta revolución es, pues, en un sentido real, la emancipación del individuo" 11 .

En efecto, si nos preguntamos cuál fue el elemento fundamental de las nuevas formas de vida económica que entrañaba el sistema capitalista coincidiremos en una marcada acentuación en lo individual: "...Capitalismo se identifica con el sistema de iniciativa individual absolutamente libre: un sistema (...) en que los hombres se comportan como agentes libres en la búsqueda de su sustento y en que no hay compulsiones ni restricciones legales"12.

Son los individuos los que utilizando su audacia e iniciativa en el juego económico pueden satisfacer no sólo sus necesidades, sino las_necesidades de la sociedad, pues el bienestar social ya no tendrá como medida y cánon a lo colectivo de las instituciones -la Iglesia con sus normas morales o el Estado con sus leyes- para asegurar el bien común de todos los ciudadanos. Todo lo contrario, los individuos serán desde este momento el punto de partida para generar el bienestar social en condiciones en las cuales su libertad no sea entorpecida.

Este afán individualista de la nueva forma de vida económica, propugnado por la burguesía, pareciera haber tenido sus ambiguedades en algunos momentos concretos de su historia. $\mathrm{Si}$ vemos que tanto la burguesía como su sistema económico fueron adversos a toda compulsión legal, e inclusive ético-religiosa, no obstante hubo situaciones en las que sucedió todo lo contrario. El economista inglés $M$. Dobb sostiene que "si bien en sus comienzos el capitalismo hizo la guerra a los privilegios monopolistas de gremios artesanales y corporaciones de mercaderes que estorbaban su camino, no se mostró luego del todo adverso a aceptar privilegios económicos y regulación estatal de la actividad económica en interés propio, como lo prueba la posterior historia del mercantilismo".13

Por su parte, Laski no cree que estas ambiguedades representaran una pérdida de identidad burguesa; más bien, parten de todo un proceso histórico que involucra al Estado y su proceso de secularización, en el cual la burguesía, con el propósito de ascender, hace alianza con la corona para obtener los beneficios económicos que ésta le pueda proporcionar; luego, justifica el no 
intervencionismo, cuando los cimientos de su emancipación económica están preparados.

Como quiera que sea, no se puede obviar la resistencia burguesa ante los monopolios reales de los siglos XVI y XVII, en donde quedan sentados unos supuestos económicos de individualismo competitivo.

Los tres fenómenos individualistas de la Modernidad que sumariamente acabamos de observar constituyen el fondo histórico por donde ha germinado el individualismo liberal. Pasemos ahora a explorar el significado y los enfoques de este último.

\subsection{Significado y enfoques del individualismo liberal}

Trataremos de presentar aquí el significado o concepto de lo que se entiende por individualismo liberal. Para ello hemos tomado las definiciones de Bobbio y Xifra Heras. Seguidamente, expondremos los variados enfoques de este individualismo liberal dentro de la tradición del liberalismo clásico. Estos enfoques los resumen magistralmente estudiosos como Macpherson, Mairet, Santiago Nino y Bobbio.

Norberto Bobbio dice enfáticamente: "sin individualismo no hay liberalismo"14. Y es que el individualismo, según él, es la condición sine qua non de la teoría liberal, pues, representa una verdadera revolución copernicana en el plano político. El problema del Estado ya no será visto a partir de su autoridad o poder, sino desde los individuos ("súbditos" o "ciudadanos") que realmente lo crearon para proteger sus intereses.

Bobbio definirá el individualismo liberal como una teoría que "separa al sujeto del cuerpo orgánico de la sociedad y lo hace vivir, por lo menos durante una parte de su vida, fuera del seno materno...(...). Reinvindica la libertad individual tanto en la esfera espiritual como económica contra el Estado; (...) Pone en evidencia la capacidad de autoformación, de desarrollar sus propias facultades, de progresar intelectual y moralmente en condiciones de máxi- 
ma libertad de vínculos externos impuestos en forma coercitiva"15.

Por su parte, Jorge Xifra Heras nos dice que el individualismo liberal "considera al hombre como átomo aislado que en sí pone su propia fuerza de conservación y desarrollo, como verdadera mónada social que no admite más relación entre los individuos que su contacto mecánico."16

La relación entre el individualismo liberal y el individualismo modemo no es remota; áquel ha bebido de las fuentes de éste como ya lo observamos en el apartado anterior. De esta manera, se ha venido conformando una antropología liberal, que si bien es cierto no ha sido un cuerpo teórico unitario - tal como lo podría sugerir ese apelativo-, al menos registra bajo ese título diversos modos de enfocar el problema. Veámoslo a continuación.

A) El individualismo posesivo y mercantil.

Para C.B. Macpherson, el individualismo liberal del siglo XVII era el correlato de la realidad económica de ese período. Una realidad netamente mercantilista que podría recibir el nombre de "sociedad posesiva de mercado", pues se caracterizaba por hallarse dividida en clases (los propietarios o quienes poseen tierras y capital y los trabajadores) y porque ella misma estaba constituida por relaciones económicas de competencia y hostilidad entre los mismos individuos. El paradigma antropológico de esta sociedad posesiva de mercado sería un "individualismo posesivo". Macpherson resume las características de este individualismo en una serie de proposiciones:

- a) Los hombres son "humanos" si son libres de la dependencia de los demás.

b) La libertad de los demás implica una autonomía en las relaciones con los otros, al menos que cada individuo tenga la iniciativa de entrar voluntariamente a ellas por su propio interés.

c) "El individuo es esencialmente el propietario de su propia persona y de sus capacidades, por las cuales nada debe a la sociedad".

d) Los individuos pueden alienar su capacidad para trabajar.

e) "La sociedad humana consiste en una serie de relaciones mer- 
cantiles".

- f) Las obligaciones y reglas que garanticen la libertad de un individuo no pueden menoscabar las libertades de los demás.

- g) Los individuos han creado la sociedad política para garantizar sus personas y bienes 17 .

En estas afirmaciones se ponen de manifiesto varias cosas: la primera, que cada individuo se posee a sí mismo, se pertenece, es dueño y propietario de su propia persona. Este "sí mismo" indicaría su persona y sus capacidades que lo acreditan como un ser racional y libre de las voluntades ajenas.

Fijémonos que en las dos primeras afirmaciones se insiste en la libertad o independencia de los otros. Por eso mismo, los individuos son "humanos" en cuanto son libres, es decir en tanto no dependan de las voluntades de los demás. Estos últimos se convertirían en límites exteriores a su propiedad personal.

En segundo lugar, la auto-pertenencia le viene dado a cada individuo por "naturaleza" y, por tanto, la sociedad tiene que reconocerla y defenderla. Sobre ésto la última proposición es muy explícita: reafirma el individualismo iusnaturalista que vimos anteriormente.

En tercer lugar, hay una referencia al individualismo económico cuando se sostiene que la sociedad humana se reduce a relaciones mercantiles. De hecho, Macpherson afirma que "el individualismo posesivo" alude a una sociedad en la que las relaciones sociales son relaciones de mercado. En ellas no sólo hay oferta y demanda de bienes y productos, sino también de individuos que han cedido libremente sus capacidades laborales a cambio de salarios. Es más, se pone de manifiesto los ideales de la nueva sociedad económica que eran la extracción y acumulación desmedida de riqueza sin restricciones externas de carácter moral o religioso.

\section{B) El individualismo ético}

Según Gérard Mairet el individualismo liberal no sólo apunta a consideraciones mercantiles, sino también a una dimensión ética. En tal sentido se puede habiar de un conjunto de valores 
inmanentes a un hecho primario: la propiedad.

El tema de la propiedad, a consideración de Mairet, puede remontarse hasta la filosofía de Locke como también a las doctrinas de la economía política burguesa clásica.

El liberalismo a partir de la idea lockeana de la "propiedad" -condición básica para que todo hombre sea libre y se pertenezca a sí mismo-, ha hecho suyo este argumento, elaborando la ecuación: libertad = propiedad.

La antropología moral del liberalismo se basa en la concepción de la persona como ser que se pertenece a sí mismo: "Decir yo soy propietario de mi propio cuerpo supone construir una representación del hombre, de su dignidad, supone hacer del propietario una persona moral. Es reconocer en ese Yo las cualidades de un sujeto moral"18. De esta manera, sería un acto anti-ético el despojar a un hombre de su pertenencia a sí mismo contra su voluntad, pues se estaría atentando contra un atributo que, a todas luces, le es propio y del cual nadie puede disponer a su antojo.

Así, los propietarios, u hombres libres, que poseen sus propiedades privadas: tierras, bienes, fuerza de trabajo, etc., constituirán una comunidad moral, una comunidad de "yos" que se reconocen mutuamente como "personas" a partir de su libertad. Libertad que, como hemos visto, se encuentra inscrita en su propia naturaleza.

En esta misma línea ética, Carlos Santiago Nino expresa el principio de individualismo dentro de la teoría liberal como un principio de "inviolabilidad y autonomía de la persona".

Santiago Nino dice que el liberalismo se apoya en la máxima kantiana de concebir a los hombres como fines y no como medios $y$, por este motivo, no existe ninguna justificación para sacrificar a los individuos (sus personas y bienes) en favor de una colectividad o "entidad supraindividual" sin tomar en cuenta su consentimiento19.

\section{C) El individualismo como atomismo}

Otra manera como se ha considerado el tema del individualismo dentro de las teorías liberales es a partir de una visión atomista. Esta visión se funda en las teorías iusnaturalistas y contractualistas 
y tiene a Hobbes como uno de sus iniciadores, por cuanto consideraba, en un primer momento, a los individuos aislados, autónomos y fuera de todo compromiso social. Los individuos serían mecanismos autónomos que se movilizan gracias a una estructura interna, gozando de una amplia e irrestricta libertad e igualdad de condiciones. Aunque esta teoría tenía la pretensión de justificar la necesidad de una sociedad civil centralizada en la figura del Leviatán o dios mortal, los teóricos liberales posteriores se dieron cuenta de la importancia que esta argumentación revestía. Así, a partir de un individualismo antisocial, egoísta, antisolidario y movido por sus pasiones e intereses, se fue construyendo una teoría, atemperada en algunas ocasiones por principios éticos, que primaba al individuo sobre lo colectivo; o dicho de otra manera, era la parte la que tenía anterioridad al todo. 20

Esta "anterioridad" significa para el individualismo liberal dos aspectos importantes: uno, de orden cronológico, que estima como momento fundante a cada individuo y como momento fundado, a la sociedad civil. Aquí vemos claramente la postura del contractualismo porque ratifica la creación de la sociedad civil a partir de la suma de voluntades individuales para superar un estado de guerra y anarquía. El otro aspecto importante es más de orden jurídico, pues los individuos son considerados anteriores "al todo" en cuanto son sujetos de derechos inalienables $y$, por ello, sus intereses merecen una prioridad.

\section{D) El individuo y el Estado}

El individualismo liberal queda completado con la idea de Estado y de sus funciones en la sociedad.

La idea de autoridad política entre los autores liberales parte de una distinción: la distinción entre lo privado y lo público, entre un dominio intra y un dominio extra. El ámbito privado es esencialmente el mundo individual, la vida, las acciones de las personas, 0 en lenguaje del liberalismo, la propiedad (tanto la propiedad personal como los bienes extraídos del trabajo). El ámbito público queda reservado a la autoridad política y a todas sus acciones orientadas a lograr la seguridad de los individuos.

La noción que se tenga de cómo empleará el Estado sus esfuer- 
zos y recursos para conseguir el anterior fin es lo que va a distinguir la idea liberal de Estado de otras concepciones políticas.

Tanto Carlos Fayt como Bobbio coinciden en señalar los inicios de ese Estado a partir de la decadencia progresiva del poder absolutista en algunas naciones europeas. Básicamente se tiene como paradigma las revoluciones de Inglaterra en 1688, de Norteamérica en 1776 y de Francia en 1789.21 Las protestas contra los monopolios reales por sus imposiciones económicas, el debilitamiento de los privilegios nobiliarios, la divulgación por algunos juristas modernos de la idea de "soberanía del pueblo" y del "derecho a resistencia", la erosión de los Estados confesionales, el fuerte espíritu político antipaternalista fueron algunos de los acontecimientos que-propiciaron el surgimiento del Estado liberal.

¿Cuál es el papel funadamental que el liberalismo clásico asigna al Estado? Quizá la frase de Wilhelm von Humboldt (1767-1835) nos sea muy orientadora: "Que el Estado se abstenga totalmente de velar por el bienestar positivo de los ciudadanos y se limite estrictamente a velar por su seguridad contra ellos mismos y contra los enemigos del exterior, no restringiendo su libertad con vistas a ningún otro fin último"22. Uno de los elementos que nos llama la atención en esta frase es el límite al poder político. Sin embargo, hay que hacer una distinción entre los límites del poder político y los límites de sus funciones.

Desde las teorías liberales, el Estado se concebirá como una autoridad limitada tanto en sus poderes como en sus funciones. Por ello no causa extrañeza encontrar en muchos tratados liberales o sobre el liberalismo, una definición de esta corriente como una teoría del Estado limitado en contraposición al Estado absoluto o como una teoría del Estado mínimo en contraposición a un Estado injerente en la vida privada.

Cuando el liberalismo habla de límites a los poderes del Estado hace alusión a un "Estado de derecho", es decir en el que el poder esté regulado por leyes constitucionales que eviten toda clase de agravios y perjuicios a los individuos. Las teorías del moderno iusnaturalismo sirvieron de plataforma ideológica para limitar el poder político al considerar derechos individuales de carácter inalienable previos al Estado; el Estado no podría abusar ni utili- 
zar para su conveniencia dichos derechos.

Es más, la autoridad política no sólo reconocería en cada individuo el ser depositarios de derechos naturales, sino que debería también "constitucionalizarlos", es decir, hacerlos positivos. El reconocerlos legalmente como "derechos inviolables" significa ocuparse de la seguridad de aquéllos.

Bobbio sostiene que el Estado de derecho avalado por el liberalismo posee ciertos mecanismos inhibitorios al despotismo y absolutismo estatal. Estos mecanismos pueden inferirse de algunos tratados liberales, tal como los Dos ensayos sobre el gobierno civil de Locke. Entre ellos están: una fiscalización a las acciones del poder ejecutivo por parte del poder legislativo; el control a las acciones del poder legislativo por parte de una "corte jurisdiccional"; autonomía de los gobiernos locales con respecto al gobierno central; autonomía del poder judicial con respecto al poder político. 23

Cuando el liberalismo habla de límites a las funciones del Estado no está haciendo alusión más que a la idea de un "Estado mínimo". Fue Humboldt quien nos afirmó inicialmente sobre la abstinencia total del Estado para entrometerse en la esfera privada o en "el bienestar positivo" de los ciudadanos.

En su "Ideas para un ensayo de determinación de los límites que circunscriben la acción del Estado", Humboldt cree que de la misma forma como el Estado se ha mostrado eficiente en el cuido de la cosa pública, así también los individuos han llegado a la suficiente madurez y autonomía como para cuidarse ellos mismos, con gran eficacia, de sus propios asuntos. Toda intervención del Estado en los asuntos privados de los individuos merece ser reprobada, pues "...la libertad de la vida privada aumenta exactamente en la misma medida en que disminuye la libertad de la vida pública..."24.

Es aqui donde tiene resonancia el individualismo económico que observamos en páginas anteriores. En tal sentido, "vida privada" significará el libre juego económico de los individuos. La preocupación del Estado debe ser el de garantizar la seguridad de los ciudadanos en contra de cualquier fuerza atentatoria a sus derechos. Nada más. 
También aquí tiene resonancia el tema de "la variedad". Mientras el Estado no se entrometa en los asuntos privados, mayor garantía habrá para que cada individuo sea él mismo; dicho en otras palabras, posea sus cualidades particulares y peculiaridades. Bobbio denomina a este fenómeno como "la fecundidad del antagonismo" y, a su juicio, constituye un tema característico e innovador del pensamiento liberal.25 Para el liberalismo clásico mientras más "variedad de caracteres", pensamientos, posiciones y posturas haya en la sociedad mayores serán los beneficios para los mismos individuos, pues se estaría respetando la forma de ser y pensar de cada uno de ellos. En una palabra, se estaría salvaguardando su libertad interior.

Es muy común encontrar en la literatura del liberalismo el apelativo de "mal necesario" que se le adjudica al Estado. Descifrándolo tenemos que, es un "mal" porque todo hombre libre desearía seguir disfrutando plenamente de su libertad natural, siguiendo sus propios intereses y aspiraciones sin "alguien" extraño que pudiese interferir en sus acciones; sin embargo, se hace "necesario" desde el momento en que puede existir alguna violación a las garantías individuales por otros individuos o por otra nación, siempre y cuando no se extralimite en sus funciones.

En suma, estos cuatro enfoques del individualismo liberal que hemos presentado son complementarios y por ninguna razón deben verse de forma antitética. De hecho, lo que muestran son facetas de una premisa compartida por estas posturas; premisa que, como dijimos anticipadamente, se constituye en su presupuesto básico. Ahora bien, no está demás decir aquí que la variedad de enfoques sobre el individualismo liberal ha contribuido a la existencia de un amplio espectro de nociones sobre el liberalismo.

Pero volviendo a nuestro problema, pasemos ahora a completar la exposición del individualismo liberal con la temática de la libertad.

\section{La libertad individual}

i Bobbio afirmaba que sin individualismo no hay liberalismo, nosotros podríamos decir que sin libertad no hay un auténtico 
individualismo liberal. Basta recorrer el apartado precedente para darnos cuenta de la insistencia con que aparece este concepto junto al individualismo.

Para Jordi López Camps la libertad se convierte en el núcleo principal del liberalismo. Pero esta libertad liberal debe entenderse como:

a) Una libertad individual y personal. La coacción que unos hombres ejercen sobre otros a nivel social queda reducida al mínimo.

b) Libertad política. Entendida como el derecho a la libre elección del gobierno.

c) Libertad interior. Es cuando los hombres se guían por su propia y deliberada voluntad. La razón es el eje de las acciones humanas y no sus impulsos y circunstancias momentáneas. 26

Sin embargo, las definiciones y nociones de libertad que ha conocido el liberalismo tanto clásico como contemporáneo han sido variadas. Para cerciorarnos de este amplio mundo y para contribuir a la comprensión del individualismo liberal, veamos ahora dos de los enfoques más importantes de este concepto.

\subsection{Libertad negativa y libertad positiva}

Es Norberto Bobbio quien ilustra de una manera muy interesante los dos significados más renombrados de "libertad" dentro de la filosofía política. Ellos son: libertad negativa y libertad positiva.

Por libertad negativa "se entiende, en el lenguaje político la situación en la cual un sujeto tiene la posibilidad de obrar o de no obrar, sin ser obligado a ello o sin que se lo impidan otros sujetos".27 Por eso suele llamársele también "libertad como ausencia de impedimentos" o "libertad como ausencia de constricción". Su "negatividad" deviene de una carencia o ausencia de algo: precisamente, de todos los límites o impedimentos exteriores.

Por libertad positiva entiende "...la situación en la que un sujeto tiene la posibilidad de orientar su voluntad hacia un objetivo, de tomar decisiones, sin verse determinado por la voluntad de 
otros". 28 Ha tenido como sinónimos los conceptos de "autodeterminación" y "autonomía". Su "positividad" se deriva de la la voluntad como el impulso que mueve las aspiraciones humanas hacia un objetivo.

Tanto una libertad como la otra derivan de una distinción histórica. Según Bobbio fue Benjamin Constant -en su célebre discurso ante el Ateneo Real de Paris en 1818- quien estableció tal distinción a partir del mundo clásico (antiguos) y del mundo modemo. En ese sentido, la libertad negativa sería la "libertad de los modernos", pues fueron éstos quienes aspiraban al disfrute de su vida privada sin la intervención del Estado. En cambio, la libertad positiva sería la "libertad de los antiguos", en cuanto era propia del mundo clásico o de la polis: entre más distribuido estuviese el poder social dentro de la polis más desarrollada y autárquica se convertiría. Sin embargo, Bobbio no esta completamente de acuerdo con la anterior distinción porque cree que ambas libertades se dieron en mayor o menor medida en las dos épocas.

Así mismo, Bobbio es consciente de que ha habido una distinción de ambas libertades a partir del sujeto histórico. Se ha considerado que el sujeto histórico de la libertad negativa es el individuo quien lucha contra toda clase de impedimentos o constricciones. Por esa razón se le ha llamado "libertad del burgués" o "libertad respecto del Estado". Sus contenidos son los derechos civiles o individuales. Por otro lado, se considera que el sujeto histórico de la libertad positiva es "el ente colectivo". Es decir, se refiere a la voluntad colectiva o general. En ese sentido se le ha llamado también "libertad del ciudadano", "libertad del Estado" o del "ente colectivo estatal". Mas, tampoco Bobbio está de acuerdo con dicha distinción, pues ambas libertades pueden referirse a un mismo sujeto histórico; con ello estaría invalidando toda propuesta tajantemente parcializada como las anteriores.

Ahora bien, aunque la tradición liberal y la filosofía política utilicen estos dos conceptos, Bobbio prefiere denominar a la libertad negativa como libertad de obrar y a la libertad positiva como libertad de querer. "Obrar" y "querer" serían los términos más apropiados para estos dos tipos de libertad, pues la primera indicaría una acción que no se ve obstaculizada y que, por tanto, pue- 
de llevarse a cabo. La segunda indicaría una "cualificación de la voluntad", es decir, el querer que es libre de alcanzar un objetivo.

Bobbio incluso va más allá: ambos tipos de libertad pueden corresponderse con las concepciones deterministas e indeterministas. Basta decir que el determinismo señala una situación en la cual el curso de los acontecimientos carece de límites, para afirmar que es compatible con la libertad negativa. Es decir, mientras el curso natural o determinado de las cosas no se vea interferido por alguna variable extraña, su desenvolvimiento será el esperado. Y ésto es, a juicio del filósofo italiano, tan próximo a la libertad antes dicha. Por otro lado, existe una correspondencia entre el indeterminismo con la libertad positiva. Sólo veamos que el primero apela a las capacidades de los sujetos para variar el curso de sus acciones con el fin de perseguir las metas deseadas.

Para finalizar diremos que ante la cuestionante de si las dos libertades son compatibles o no, Bobbio no puede ser más claro al respecto: "la verdad es que las dos libertades no son en absoluto incompatibles, digan lo que digan los rígidos defensores de una y otra. No sólo no son incompatibles sino que se refuerzan una a la otra".29

\subsection{Las "escuelas" de la libertad}

Otra manera muy original de enfocar el problema de la libertad individual dentro del liberalismo es la que nos propone José Merquior.

Según él es posible distinguir tres escuelas (Inglesa, francesa y alemana) que han tenido una forma muy peculiar de concebir este problema, debido a sus particulares condiciones socio-históricas 30 ; pero, sin lugar a dudas, estas concepciones de libertad, en última instancia, son complementarias, tal como lo apuntó anteriormente Bobbio. La categoría de "escuela" no señala una homogeneidad de autores o de sus formulaciones, ni tan siquiera su proximidad temporal sino, más bien, algo común que comparten teóricamente. Veámoslas a continuación.

1. La tendencia inglesa, en la cual se sitúan Hobbes, Locke, Bentham, Mill, concebía la libertad como la ausencia de obstáculos y límites exteriores. Esta libertad era claramente negativa, pues 
señalaba una ausencia de coerción. Merquior sostiene que se trata de una libertad-contra, es decir, contra cualquier dominio o poder exterior. Para ilustrarlo veamos el caso de Hobbes. Este filósofo inglés sostenía que la libertad era, propiamente hablando, ausencia de oposición o impedimentos exteriores y que, como tal, podía ser aplicada tanto a los organismos irracionales como a los racionales. En el caso de los hombres, Hobbes afirma lo siguiente: "es un hombre libre quien en aquellas cosas de que es capaz por su fuerza y por su ingenio, no está obstaculizado para hacer lo que desea". 31

Cabe señalar que la concepción inglesa de la libertad, como algo "negativo" o "contra de-", no fue un fenómeno aislado o azaroso de la convulsionada historia política de Inglaterra. Autores como Locke y Mill la utilizaron como una bandera a favor de los individuos para otorgarles mayores espacios de_autonomía y realización privada. Y, en contra del Estado, para limitar sus funciones y poderes en la vida pública.

2. La escuela francesa está representada por J.J. Rousseau. Según Merquior el ideal de libertad en Rousseau no estaba en contra del individualismo. Más bien se enfrentaba al particularismo o patrimonialismo como fenómeno político de Francia. Por esa razón era una libertad que primaba la autonomía de la colectividad; o dicho en otras palabras, ante la concepción de que sólo el Rey es libre y soberano, la libertad roussoniana apelaba al autogobierno y a la autonomía política del pueblo. Veamos lo que nos dice Rousseau en su Contrato social: "La voluntad constante de todos los miembros del Estado es la voluntad general; por ella son ciudadanos libres. Cuando se propone una ley en las asambleas del pueblo, no se trata precisamente de conocer la opinión de cada uno de sus miembros y de si deben aprobarla o rechazarla, sino de saber si ella está de conformidad con la voluntad general, que es la de todos ellos. (...) Esto supuesto, es evidente que el carácter esencial de la voluntad general está en dar pluralidad; cuando ésta cesa, la libertad cesa..." 32 .

3. Para la escuela alemana (en donde se sitúan Kant, Humboldt y Hegel, entre otros) el concepto destaca la autorrealización del potencial humano. Por tanto, era una concepción de libertad positiva o libertad para, pues los individuos al ser capaces de 
autogobernarse podrán ir alcanzando sus propias metas, fines y objetivos. Sin embargo, la concepción alemana no deslegitima el papel que desempeña la educación de la personalidad con el fin de obtener el ideal antes mencionado. Por eso no es extraño que autores como Humboldt hayan afirmado que libertad y cultura caminan a la par.

Ahora bien, veamos qué nos dice Humboldt con respecto a los supuestos anteriores: "El verdadero fin del hombre — no aquel que le señalan inclinaciones variables, sino el que le prescribe la eternamente inmutable razón- es el más elevado y proporcionado desarrollo de sus fuerzas en un todo armónico. Y para ello, la condición primordial e inexcusable es la libertad." 33 Si el medio en donde los individuos se realizarán posee todas las características armónicas posibles, es decir, donde no haya fricciones de ninguna índole, entonces sus potencialidades se verán favorecidas. Sin embargo, Humboldt agrega un ingrediente más: la variedad de situaciones. Entre menos uniformes y estáticas sean las situaciones que se le presenten a los hombres, mucho mejor será su desenvolvimiento. Pues hasta los hombres más libres e independientes adquieren un desarrollo muy limitado de su personalidad en contextos uniformes.

En suma, la tendencia alemana apostará, según Merquior, por una concepción de libertad que implica el despliegue de los individuos a mayores grados de autonomía y realización personal.

\section{Conclusiones}

1. Dado que el presente trabajo tenía como objetivo mostrar el significado y las características del individualismo liberal, iniciamos haciendo una suscinta descripción de las nociones y raíces del liberalismo. Como pudimos observar, no es fácil lograr una definición única de esta corriente debido a muchas variables históricas y conceptuales. Históricas, porque ha bebido de innumerables hechos, corrientes y fenómenos de la Modernidad. Conceptuales, porque entre sus teóricos no ha habido un consenso de sus postulados - como es el caso de la libertad-, por lo que lo ha llevado a diversas interpretaciones.

2. En cuanto al individualismo liberal hemos visto, primera- 
mente, que ha tenido sus raíces en otros "individualismos". Y ello se debe a que la cultura Moderna o la "Modernidad" se centra en el sujeto. Pues bien, este individualismo liberal tiene varias facetas por donde es posible abordarlo. Claro está, todas ellas están vinculadas de tal modo que no deben verse aisladas o inconexas. Estas facetas las hemos agrupado en cuatro bloques. La primera de ellas (presentada por Macpherson) se centraba en la autonomía de los individuos ante las voluntades ajenas, así como también en considerar a la sociedad en relaciones puramente mercantiles.

La segunda era de carácter ético (Mairet y Santiago Nino). Ella mostraba el derecho a la inviolabilidad de la persona desde el momento en que cada hombre era propietario de sí mismo. La tercera enfatizaba en una visión atomista (Bobbio) en la cual Hobbes era considerado como el máximo representante. La sociedad será, a partir de esta visión, un conglomerado de individuos que buscan sus fines particulares.

La cuarta, reiteraba en la relación individuo-Estado. Fue Humboldt quien nos ilustró, juntamente con Bobbio, cuáles eran los límites del Estado que favorecerían mayores grados de acción en la esfera individual. A menor injerencia de la esfera estatal en la vida privada, mayores serán las condiciones que posibiliten una pluralidad de individualidades en la sociedad.

3. Muy unido al tema del individualismo liberal está el problema de la conceptuación de la libertad. Como pudimos ver, las acepciones de "libertad" dentro del liberalismo han sido variadas. Sin embargo, tal parece que dos de ellas han merecido un detallado estudio y análisis por los especialistas en la materia. Ellas son la libertad negativa y la libertad positiva. La primera ha sido entendida como una libertad contra las injerencias de los otros. La segunda, como una autorrealización individual.

\section{BIBLIOGRAFIA}

1. Bobbio, N., Liberalismo y democracia, México: FCE, 1994.

2. Bobbio, N., Igualdad y libertad, Barcelona: Paidó, 1993.

3. Bobbio, N. y Borero, M., Sociedad y estado en la filosofia moderna. El modelo iusnaturalista y el modelo hegeliano-marxiano, México: FCE, 1986. 
4. De Sebastian, L., "El neoliberalismo: una negación del liberalismo" en Realidad económica y social, N. 11 (1989) PP. 419-436.

5. Dobb, M., Estudios sobre el desarrollo del capitalismo, México: Siglo XXI editores, 1986.

6. Fasso, G., Historia de la filosofía del derecho, Madrid: Pirámide 1982, T. II.

7. Fayt, C., El estado liberal moderno. Historia del pensamiento político, Buenos Aires: Editorial Plus Ultra 1973.

8. Hobbes, T., Leviatán, Buenos Aires: FCE, 1992.

9. Humboldt, W.v., Escritos políticos, México: FCE, 1983.

10. Laski, H., El liberalismo europeo, México: FCE, 1992.

11. López Camps, J., "Diálogos para un amigo neoliberal" en El neoliberalismo en cuestión, Cantabria: Sal Terrae, 1993.

12. Macpherson, C.B., La teoría polílica del individualismo posesivo, Barcelona: Fontanella, 1970.

13. Mairet, G., "El liberalismo: presupuestos y significaciones" en CHATELET, F. (Comp.), Historia de las ideologias. Saber y poder, México: Premia editores, 1980, T. III., Pp. 116-140.

14. Martín, A. v., Sociología del Renacimiento, Madrid: FCE, 1981.

15. Merquior, J.G., Liberalismo viejo y nuevo, México: FCE 1993.

16. Rousseau, J.J., El contrato social o principis de derecho polfico, México: Porrúa, 1977.

17. Santiago Nino, S., "Las concepciones fundamentales del liberalismo" en $R e$ vista latinoamericana de filosofía, N. 2 (1978) Vol. IV, p. 142-144.

18. Troeltsch, E., El protestantismo y el mundo moderno, México: FCE, 1967.

19. Xifra Heras, J., Introducción al estudio de las modernas tendencias políticas. Ensayo sobre la intensidad y subjetivación del poder., Barcelona: Bosch, 1954.

\section{Notas}

1. Este artículo es una ligera modificación al capítulo primero de mi tesis de licenciatura "La compatibilidad del individualismo filosófico de Leibniz con el individualismo liberal".

2. Bobbio, N., Liberalismo y democracia, México: FCE, 1994, p. 9. Bobbio está citando a Benjamin Constant.

3. Merquior, J. G., liberalismo viejo y nuevo, México: FCE 1993 p. 18-19.

4. Ruggiero, G., Historia del liberalismo europeo, citado por FAYT,C., El Estado liberal moderno. Historia del pensamiento político, Buenos Aires: Editorial Plus Ultra 1973, Vol. VII, p. 279.

5. Merquior, J. G., O. C., p. 59.

6. Laski, H., El liberalismo europeo, México: FCE 1992, p. 74. 
7. Troeltsch E., El protestantismo y el mundo moderno, México: FCE 1967, p. 82.

8. Cfr. Fasso, G., Historia de la flosofía del derecho, Madrid: Pirámide 1982, T. II, p. 82; Bobbio, N. y Bobero, M., Sociedad y estado en la filosofia moderna. El modelo iusnaturalista y el modelo hegeliano-marxiano, México: FCE 1986, p. 16.

9. Fasso, G., o. c., p. 79.

10. Bobbio, N. y Bobero, M., o. c., p. 18-19.

11. Laski, H., o. c., p. 25-26. Ver también a Martin, A. v., Sociología del renacimiento, Madrid: FCE 1981, p. 19-20.

12. Dobb, M., Estudios sobre el desarrollo del capitalismo, México: Siglo XXI editores, p. 17-18.

13. Dobb, M., o. c., p. 40-41.

14. Bobbio, N., o. c., p. 16.

15. Ibid., p. 51-52.

16. Xifra Heras, J., Introducción al estudio de las modemas tendencias polfticas. Ensayo sobre la intensidad y subjetivación del poder, Barcelona: Bosch 1954, p. 84.

17. Macpherson, C.B., La teoría política del individualismo posesivo, Barcelona: Fontanella 1970, p. 225-226.

18. Mairet, G., "El liberalismo: presupuestos y significaciones" en CHATELET,F. (Comp.), Historia de las ideologías. Saber y poder., México: Premia editores 1980, T. III, p. 128.

19. Santiago Nino, S., "Las concepciones fundamentales del liberalismo" en Revista latinoamericana de filosofía, N. 2 (1978) Vol. IV, p. 142-144.

20. Cfr. Bobbio, N., o. c., p. 52.

21. Cfr. Fayt, C., o. C., p. 11; Bobbio, N., o. c., p. 12-15.

22. Humboldt, W. V., "Ideas para un ensayo de determinación de los límites que circunscriben la acción del Estado" (1791) en Escritos políticos, México: FCE 1983, p. 117.

23. Bobbio, N., o. c., p. 19-20.

24. Humboldt,W.V., o. c., p. 90.

25. Bobbio, N., o. c., Pp. 27-31.

26. López Camps, J., "Diálogos para un amigo neoliberal" en El neoliberalismo en cuestión, Cantabria: Sal Terrae 1993, p. 120-121.

27. Bobbio, N., Igualdad y libertad, Barcelona: Paidos 1993, p. 97.

28. Ibid., p. 100 .

29. Ibid., p. 119.

30. Merquior, J., o. c., p. 25.

31. Hobbes, T., Leviatan, Buenos Aires: FCE 1992, Parte II Cap. XXI, p. 171.

32. Rousseau, J. J., El contrato social o principios de derecho polftico, México: Porrúa 1977, Libro IV Cap. II, p. 57.

33. Humboldt, W. v., "Ideas para un ensayo de determinación de los límites que circunscriben la acción del Estado" en o. c., p. 94. 